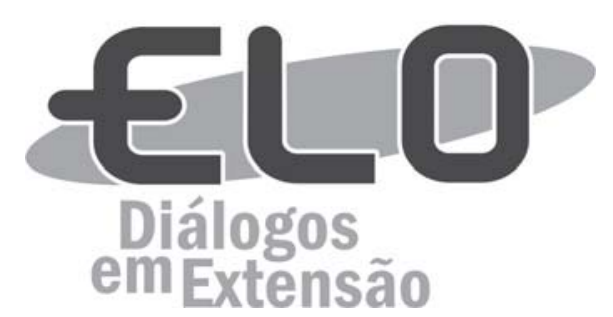

\title{
Estudo da sustentabilidade em agroecossistemas orgânicos na Amazônia Mato-Grossense, Brasil
}

\author{
Inês Caroline de Lima Proença ${ }^{1}$, João Aguilar Massaroto ${ }^{2}$
}

\begin{abstract}
Resumo: O presente trabalho teve como objetivo inferir as condições do ideal de sustentabilidade em agroecossistemas orgânicos de base familiar no município de Alta Floresta/MT. Foram avaliados os atributos dos agroecossistemas produtivos familiares, por meio da mensuração de 26 indicadores de sustentabilidade em cinco unidades produtivas orgânicas, utilizando-se como ferramenta a metodologia "MESMIS" (Marco para Avaliação de Sistemas de Manejo de Recursos Naturais Incorporando Indicadores de Sustentabilidade). Verificou-se que a riqueza de espécies manejadas nos agroecossistemas orgânicos familiares amazônicos é um fator chave de sucesso na manutenção da sua resiliência e estabilidade. Por outro lado, observou-se a necessidade de adoção de técnicas agroecológicas, uma vez que estas interferem diretamente na autogestão dos agroecossistemas.
\end{abstract}

Palavras-chave: Agroecologia. agricultura familiar. metodologia Mesmis.

Área Temática: Agroecologia. Meio ambiente.

\section{Study of sustainability in organic agroecosystems in the mato-grossense amazonia, Brazil}

Abstract: The present article aims to infer the conditions of the ideal of sustainability in family - based organic agroecosystems in the municipality of Alta Floresta /MT. The attributes of productive agroecosystems family were assessed by mensuration of 26 sustainability indicators in five organic production units, using as a tool the methodology "MESMIS" (Framework for Assessment of Natural Resource Management Systems Incorporating Sustainability Indicators). For the data collection were idealized semi-structured questionnaires and field visits (observation). It was found that the species richness managed in Amazonian's organic family agroecosystems is a key success factor in maintaining its resilience and stability. On the other hand, it was noted as essential the need for adoption of agroecological techniques, once these interfere directly in selfmanagement of agroecosystems.

Keywords: Agroecology. Farming, Family. Mesmis methodology.

Estudio de la sustentabilidad en agroecosistemas orgánicos en la amazonia matogrossense, Brasil

Resumen: El presente artículo pretende inferir las condiciones del ideal de sustentabilidad en agroecosistemas orgánicos de base familiar en el municipio de Alta Floresta / MT. Se evaluaron los atributos de los agroecosistemas productivos familiares, por medio de la medición de 26 indicadores de sostenibilidad en cinco unidades productivas orgánicas, utilizando como herramienta la metodología "MESMIS" (Marco para la Evaluación de Sistemas de Manejo de Recursos Naturales Incorporando Indicadores de Sostenibilidad). Para la recolección de datos se idearon cuestionarios semiestructurados y visitas a campo (observación). Se verificó que la riqueza de especies manejadas en los agroecosistemas orgánicos familiares amazónicos es un factor clave

${ }^{1}$ Ms,; Agrônoma; Doutoranda Programa Pós-Graduação em Agronomia/Fitotecnia da Universidade Federal de Lavras; e-mail: inesproencaagro@gmail.com

${ }^{2}$ Dr.; Engenheiro Agrônomo; Professor Adjunto da Universidade do Estado de Mato Grosso, campus Nova Mutum;e-mail: joao.msrt@gmail.com 
de éxito en el mantenimiento de su resiliencia y estabilidad. Por otro lado, se notó como imprescindible la necesidad de adopción de técnicas agroecológicas, una vez que éstas interfieren directamente en la autogestión de los agroecosistemas.

Palabras clave: Agroecología. agricultura familiar. metodología Mesmis.

\section{Introdução}

O processo acelerado de ocupação da Amazônia mato-grossense (norte do estado), oriundo de um plano de desenvolvimento pautado na exploração não planejada dos recursos naturais, trouxe sérias consequências ao meio rural. O padrão de agricultura baseou-se, e ainda persiste, na utilização intensiva de insumos químicos, mecanização pesada e monocultivos voltados para a produtividade e lucratividade.

Em Mato Grosso, desde o período de colonização dos municípios da região médio-norte do estado, os processos de ocupação e uso dos recursos naturais, pautados sob uma ideologia de integração do território nacional e a visão da Amazônia como grande reserva de recursos naturais e grande vazio demográfico, foram baseados sob a lógica economicista/capitalista, sem políticas que continham ações relacionadas diretamente às grandes alterações na dinâmica socioambiental da região (COSTA, 2006; MARGARIT, 2013; PICHININ, 2007).

Assim como em outros municípios da região, o de Alta Floresta desde o início de seu processo de colonização, também teve sua economia estruturada na exploração inadequada dos recursos naturais (ciclos do garimpo, extração de madeira e pecuária). Porém, existem experiências agroecológicas de produção familiar na Amazônia mato-grossense, em especial nesse município, que contrapõem o atual modelo de produção agrícola adotado no Estado e que, mesmo sem apoio governamental e assistência técnica, vêm se fortalecendo na região, evidenciando a viabilidade da produção orgânica. Apesar dessas observações, não se tem muitas informações sobre a realidade desses produtores.

Na agricultura familiar, uma avaliação das práticas estudadas nos agroecossistemas proporciona a verificação dos pontos de estrangulamento enfrentados pelo segmento. Nessa avaliação, caracterizase e monitora-se os agroecossistemas, o que permite alertas para as situações de risco e para a consequente mobilização dos envolvidos, além de permitir informações e tomadas de decisões, tanto pelo produtor quanto de pessoas ligadas aos órgãos e instituições afins, com subsídios para as políticas públicas. Na análise, utilizam-se os "indicadores de sustentabilidade", considerados os instrumentos que permitem mensurar as modificações antrópicas nas características de um sistema/agroecossistema, possibilitando a inferência sobre o seu grau de sustentabilidade (MARZALL, 1999). Diante do exposto, objetivou-se, por meio de estudos de casos, inferir as condições do ideal de sustentabilidade em agroecossistemas, em propriedades de base familiar de produção orgânica.

\section{Procedimentos metodológicos}

O trabalho foi realizado no município de Alta Floresta, MT, em cinco propriedades orgânicas de base familiar. Optou-se pela abordagem metodológica "estudo de caso". Para a análise da sustentabilidade nos agroecossistemas foi utilizada a metodologia MESMIS (Marco de Avaliação de Sistemas de Manejo Incorporando Indicadores de Sustentabilidade). A escolha e a análise dos parâmetros dos indicadores de sustentabilidade foram determinadas mediante pesquisa bibliográfica, buscando contemplar as seguintes características: produção suficiente, contínua e diversificada; melhoria da capacidade produtiva do solo; conservação do ambiente; estabilidade social e autonomia da agricultura familiar (GLIESSMAN, 2005; CAPORAL e COSTABEBER, 2004; ALTIERI, 2004). Além disso, por meio dos indicadores de sustentabilidade utilizados, buscou-se refletir sobre as alterações nos atributos básicos propostos por Masera et al. (1999): produtividade, resiliência, estabilidade, equidade, adaptabilidade e confiabilidade.

Na determinação do ambiente de estudo, caracterizou-se os agroecossistemas e identificou-se os seus subsistemas, com obtenção dos dados por meio de visitas de campo, de pesquisa bibliográfica e de entrevistas. Para definição dos pontos críticos do sistema (as principais características que ameaçam ou potencializam a sustentabilidade do sistema), foram extraídas informações do Diagnóstico Rápido Participativo (DRP) e das entrevistas realizadas por meio de um questionário estruturado e semiestruturado. A elaboração do DRP foi de acordo com as orientações de Verdejo (2006).

Como ferramenta de coleta de dados, utilizou-se de técnicas como "Mapa da propriedade e recursos naturais", "Fluxograma comercial", Travessia" e entrevista. Os mapas foram construídos pelos 
agricultores com o objetivo de analisar e entender a organização produtiva do agroecossistema, com foco nos detalhes produtivos e de infraestrutura social e na criação de uma concepção compartilhada sobre a utilização do espaço e dos recursos. O fluxograma comercial teve por objetivo expor os fluxos comerciais em sua totalidade, permitindo uma análise da eficiência, debilidades e dos potenciais comerciais. A travessia, ferramenta que permitiu obter informações sobre os diversos componentes do agroecossistema (recursos naturais, vida econômica, moradias, características do solo, manejo, etc.), foi realizada por meio de uma caminhada percorrendo as diversas áreas de uso e diferentes recursos, anotando-se todos os aspectos que surgiam da observação dos participantes. Posteriormente, elaborouse o diagrama da travessia, com sistematização de todas as informações levantadas.

$\mathrm{Na}$ coleta de informações a respeito das condições socioeconômicas dos agricultores, foram elaboradas entrevistas por meio de questionário estruturado (entrevistas semiestruturadas) nas quais abordaram-se questões sobre o histórico do agricultor e da propriedade, mudanças ocorridas ao longo do tempo, motivação para trabalhar com agricultura orgânica, possibilidade e dificuldades encontradas, complementando assim as informações obtidas na coleta de dados.

Na determinação dos indicadores de sustentabilidade, buscou-se selecionar um conjunto de indicadores fáceis de mensurar, possíveis para monitorar, derivados de informações disponíveis e confiáveis, claros e simples de entender e que representassem, o máximo possível, a complexidade da realidade local. A medição dos parâmetros, ou seja, determinação dos parâmetros de análise, seguiu propostas metodológicas observadas na literatura.

A coleta de dados foi realizada por meio de entrevistas semiestruturadas e visitas a campo de dezembro de 2012 a fevereiro de 2013. Para avaliação do ideal de sustentabilidade foram selecionados 26 indicadores simples comuns aos agroecossistemas: 1 ) disponibilidade (número de fontes e acesso) de recursos hídricos; 2) uso e eficiência da água de irrigação; 3) fertilidade do solo; 4) matéria orgânica da propriedade (\% de matéria orgânica produzida na UP em relação ao total utilizado); 5) uso de implementos agrícolas; 6) área com erosão visível; 7) diversidade de técnicas agroecológicas; 8) ataque de pragas visível (análise qualitativa geral, média de todas as culturas); 9) canais de comercialização; 10) diversidade de produtos comercializados; 11) controle custo de produção; 12) crédito rural; 13) diversidade de espécies animais manejadas; 14) diversidade de espécies vegetais manejadas; 15) reserva legal/área de preservação permanente - APP (conservação); 16) estado de saúde da família; 17) condições de moradia; 18) satisfação do produtor com o sistema de produção; 19) acesso a lazer e cultura; 20) acesso à assistência técnica; 21) capacitação (treinamentos, trocas de experiências, etc); 22) permanência dos filhos na terra; 23) relação com a terra; 24) desenvolvimento e/ou adaptação de tecnologias; 25) certificação orgânica/comercialização orgânica; 26) dependência de insumos.

Nos parâmetros de mensuração dos indicadores foram atribuídas notas de 1 (um) a 5,0 (cinco), nas quais: 1,0 - representa condição não desejável; 2,0 - condição sofrível; 3,0 - condição aceitável; 4,0 - boa condição e 5,0 - condição próxima do ideal sustentável. Para a avaliação geral de sustentabilidade dos agroecossistemas, fez-se a avaliação das médias das notas dos indicadores seguindo o seguinte critério: 1,00 -1,99 "crítica"; 2,00 - 2,99 "sofrível"; 3,00 - 3,99 "regular"; 4,00 - 4,99 "boa" e 5,00 “ótima" (ideal sustentável).

Para melhor visualização dos dados, optou-se por utilizar um gráfico do tipo radial, o que representa o estado geral dos agroecossistemas, por meio dos valores atribuídos a cada indicador e que conduz a uma avaliação sistêmica e integrada.

\section{Resultados e discussões}

A área das cinco propriedades avaliadas variou de 1,22 a 20 hectares perfazendo um total de 34,5 hectares. As principais atividades agropecuárias registradas nas propriedades eram pastagem, pomar, culturas anuais (principalmente milho), áreas de pousio e quintal (muito diversificado), sendo apenas a criação de animais (principalmente ave e suíno) e horticultura, realizadas em todas as propriedades.

Constatou-se que a família é constituída de quatro pessoas, em média e que apresentam pluriatividade 3 , o que contribui para a manutenção da família. Para alguns autores, a mão de obra (agrícola e não-agrícola) exercida de forma complementar pelos membros da família se deve, na maioria

\footnotetext{
${ }^{3}$ De acordo com FULLER (1990): "A pluriatividade permite reconceituar a propriedade como uma unidade de produção e reprodução, não exclusivamente baseada em atividades agrícolas. As propriedades pluriativas são unidades que alocam o trabalho em diferentes atividades, além da agricultura familiar. [....] A pluriatividade, portanto, refere-se a uma unidade produtiva multidimensional, em que se pratica a agricultura e outras atividades, tanto dentro como fora da propriedade, pelas quais são recebidos diferentes tipos de remuneração e receitas (rendimentos, rendas em espécies e transferências)".
} 
das vezes, a fatores que comprometem a autogestão da propriedade e que obriga os agricultores a buscar uma alternativa complementar de renda (SCHNEIDER e CONTERATO, 2006; SCHNEIDER, 2003; WANDERLEY, 2009). Wanderley (2009) salienta que, na maioria dos casos, o trabalho externo à propriedade torna-se indispensável para a manutenção não só da família, mas também do próprio estabelecimento familiar. Para a autora, a pluriatividade das famílias rurais é entendida como "uma estratégia da família, a fim de, diversificando suas atividades, fora do estabelecimento, assegurar a reprodução deste e sua permanência como ponto de referência central e de convergência para todos os membros da família" (WANDERLEY, 2009, p. 193).

Desse modo, pessoas da família adquirem duas funções sociais, ou seja, a de complementar a renda familiar e a de garantir a permanência das famílias no meio rural.

Em dois dos agroecossistemas, a propriedade é do patriarca, porém a área é dividida de forma a abrigar todos os filhos com suas respectivas famílias. Cada filho tem a sua área de cultivo, porém, muitas atividades são realizadas em coletivo. Das cinco propriedades avaliadas, três são credenciadas ${ }^{4}$ pelo MAPA (Ministério da Agricultura, Pecuária e Abastecimento) por meio de uma "Organização de Controle Social" (OCS). As outras duas são propriedades não registradas ainda (em processo de transição).

\section{Indicadores de sustentabilidade de recursos hídricos e qualidade do solo}

Na Tabela 1, observa-se que, pela análise dos dados, os agroecossistemas das propriedades avaliadas, no município de Alta Floresta/MT, apresentaram médias finais entre 3,5 e 5,00 o que significa propriedades em condições regulares e ótima.

Tabela 1 - Notas atribuídas aos indicadores de sustentabilidade referentes aos recursos hídricos e qualidade do solo em cinco propriedades no município de Alta Floresta, MT. Dezembro de 2012 a Fevereiro de 2013.

\begin{tabular}{|c|c|c|c|c|c|c|}
\hline & \multirow{2}{*}{ Indicador } & \multicolumn{5}{|c|}{ Agroecossistemas } \\
\hline & & I & II & III & IV & $\mathrm{V}$ \\
\hline \multirow[t]{3}{*}{ Recursos hídricos } & Disponibilidade de recursos hídricos & 5 & 4 & 4 & 3 & 3 \\
\hline & Uso da água (irrigação) & 5 & 3 & 3 & 4 & 4 \\
\hline & Média Final & 5 & 3,5 & 3,5 & 3,5 & 3,5 \\
\hline \multirow[t]{6}{*}{ Qualidade do solo } & Fertilidade química do solo & 4 & 4 & 4 & 3 & 4 \\
\hline & Origem matéria orgânica & 5 & 5 & 4 & 5 & 4 \\
\hline & Uso de implementos agrícolas & 5 & 4 & 4 & 5 & 5 \\
\hline & Área com erosão visível & 3 & 4 & 4 & 4 & 4 \\
\hline & Diversidade de técnicas ecológicas & 3 & 5 & 3 & 5 & 3 \\
\hline & Média Final & 4 & 4,4 & 3,8 & 4,4 & 4 \\
\hline
\end{tabular}

Fonte: dados de campo. Alta Floresta/MT, dez/2012 a fev/2013.

A avaliação foi pautada no sistema de irrigação adotado (aspersão, microaspersão ou gotejamento) e sua adequação ao tipo de cultivo e ao manejo declarado comparado com as recomendações técnicas, sem desperdícios de água e possibilidade de poluição do recurso hídrico na propriedade. Nenhum agroecossistema apresentou problemas com relação a disponibilidade de recursos hídricos, uma vez que possuem mais de uma fonte de água. A riqueza de recursos hídricos na região proporciona diversidade de fontes de água passíveis de utilização nas propriedades rurais, o que contribuiu para o desempenho de regular a ótimo desse indicador. Não foram observados casos visíveis de poluição de corpos de água ou uso inadequado.

Observou-se que os equipamentos de irrigação utilizados eram adequados ao tipo de solo e cultivo, conforme recomendações técnicas, entretanto, constatou-se vazamentos e desuniformidade na aplicação da água nos sistemas de irrigação dos agroecossistemas I e III, problemas que resultavam em perda de água. Para Costa e Barros Júnior (2005), é comum se observar no campo a má conservação

${ }^{4}$ De acordo com a instrução normativa n ${ }^{\circ}$ 19, de 28 maio de 2009, há três "Mecanismos de Controle para a Garantia da Qualidade Orgânica", sendo eles a certificação, o sistema participativo de garantia (SPG) e Controle Social pela Venda Direta sem certificação. Neste último, o agricultor familiar, vinculado a uma organização de controle social - OCS (grupo, associação, cooperativa ou consórcio, com ou sem pessoa jurídica) pode realizar venda direta ao consumidor de produtos orgânicos sem certificação, porém deve ser cadastrada nas Superintendências Federais de Agricultura do Mapa ou órgão fiscalizador conveniado. 
das redes de distribuição de água, instalação inadequada e, até mesmo, manejo inadequado do sistema de irrigação. A presença de assistência técnica pode contribuir para solução dos problemas.

Com relação aos indicadores de qualidade do solo (Tabela 1) constatou-se, que os agroecossistemas apresentaram condições "regular e boa". No indicador "diversidade de técnicas ecológicas" os agroecossistemas II e V apresentaram condições "ótimas" e os demais "regular" (Tabela 1). Quanto ao indicador "área com erosão visível", apenas o agroecossistema I apresentou condição "regular" (Tabela 1). As áreas com erosão foram registradas na pastagem, com pequenos sulcos nas regiões mais declivosas ${ }^{5}$ A exploração de culturas olerícolas, em solos de baixa susceptibilidade à erosão em todos os agroecossistemas, provavelmente contribui para melhor adequação do uso do solo segundo suas classes de aptidão nos agroecossistemas. A perda de solo por erosão é um dos maiores e mais alarmantes problemas ambientais para o agronegócio (COGO et al., 2004).

Para o indicador "origem da matéria orgânica", verificou-se que o desempenho dos agroecossistemas, variou de "bom" nos agroecossistemas III e V a "ótimo" nos agrossistemas I, II e IV (Tabela 1). Para avaliação desse indicador utilizou-se a porcentagem de matéria orgânica produzida na própria unidade de produção (UP) em relação ao total utilizado. Os ideais teóricos da agricultura orgânica e da sustentabilidade, visam a autossuficiência do sistema produtivo, incluindo a mínima dependência de recursos externos. Nesse caso todos os agroecossistemas mostram-se em acordo com esses ideais.

No período de realização do estudo, os solos dos agroecossistemas apresentavam boa fertilidade, comprovada pelos atributos químicos (nutrientes) que se encontravam na faixa (teores) adequada. As boas condições de fertilidade dos solos são atribuídas ao sistema de manejo adotado (orgânico) e ao uso integrado de práticas agrícolas (CASALINHO et al., 2007). A adubação orgânica associada a outras técnicas agroecológicas favorece a manutenção do equilíbrio entre humificação e mineralização dos nutrientes. Os compostos orgânicos e estercos têm papel na nutrição das plantas e dos organismos mobilizadores de nutrientes minerais do solo, o que evidencia a importância não só da quantidade da matéria orgânica no solo, mas também da sua qualidade e diversificação (PRIMAVESI, 2008).

A matéria orgânica é um importante agente agregante do solo, tem relação direta com o poder tampão do solo, aumento da capacidade de troca catiônica (CTC) e fornecimento de substâncias fenólica e ácida orgânica (PRIMAVESI, 2002). Faz-se necessário introduzir, nos agrossistemas, práticas agrícolas que contribuam com o incremento da matéria orgânica no solo, considerando-se a quantidade e a qualidade da mesma.

\section{Indicadores de Sustentabilidade de Diversidade Vegetal e Animal}

Com relação aos indicadores de sustentabilidade de diversidade vegetal e animal, constatou-se que os agroecossistemas apresentaram condições aceitável e boa. O indicador "diversidade de espécies vegetais manejadas" foi avaliado como "ótimo", comprovado pelo cultivo de plantas hortícolas, frutíferas, pastagens e lavouras anuais, o que contribui para a sustentabilidade dos agroecossistemas (Tabela 2). Já o indicador de diversidade de espécies animais manejadas foi avaliado como sofrível (não desejáveis) nos agroecossistemas II e III, comprovado pela produção de frango semi-caipira como o único componente animal no sistema. Nos agroecossistemas I, IV e V, esse indicador foi avaliado como "regular" e "sofrível".

A manutenção e ampliação da biodiversidade dos agroecossistemas constituem o princípio inicial na busca pela sustentabilidade. A diversificação das atividades nos agroecossistemas possibilita a

Tabela 2- Notas atribuídas aos indicadores de sustentabilidade de diversidade vegetal e animal.

\begin{tabular}{|c|c|c|c|c|c|}
\hline \multirow{2}{*}{ Indicador } & \multicolumn{5}{|c|}{ Agroecossistemas } \\
\hline & $\mathrm{I}$ & II & III & IV & $\mathrm{V}$ \\
\hline Diversidade de espécies vegetais manejadas & 5 & 5 & 5 & 5 & 5 \\
\hline Diversidade de espécies animais manejadas & 3 & 1 & 1 & 2 & 2 \\
\hline Reserva legal e APP's (conservação/Preservação) & 5 & 3 & 3 & 3 & 3 \\
\hline Média Final & 4,33 & 3 & 3 & 3,33 & 3,33 \\
\hline
\end{tabular}

Fonte: dados de campo. Alta Floresta/MT, dez/2012 a fev/2013.

${ }^{5}$ Para mais estudo referente ao tema sugere-se leitura de Bertoni e Lombardi Neto (1999), Derpsch et al. (1991) e Dechen et al (2004). 
sustentação da produção por meio do restabelecimento de quantidade maior de produtos e ameniza as vulnerabilidades decorrentes do mercado, do clima e da incidência de doenças e pragas (PELINSKI et al., 2006). O aumento da diversidade contribui positivamente para o equilíbrio do ambiente, proporcionando a convivência de organismos benéficos com aqueles indesejados, propiciando o controle biológico e os fluxos energéticos naturais (CASADO et al, 2000). Ações que, se aplicadas de maneira integrada, promovem a biodiversidade no agroecossistemas são a agrofloresta, o cultivo em mosaico, consórcio e a rotação de culturas, a integração entre pecuária e produção vegetal, adubação orgânica, o pousio, o revolvimento mínimo do solo, a não supressão da vegetação espontânea, dentre outras (CASADO et al, 2000; CLARO, 2001; GLIESSMAN, 2001; ALTIERI, 2002).

Apesar de não ser o ideal, a integração na produção animal-vegetal visualizada em todos os agroecossistemas aponta um acordo com os preceitos da agricultura orgânica e com o ideal de sustentabilidade que prega a diversidade e integração de espécies para o favorecimento da estabilidade e da resiliência do agroecossistema (GLIESSMAN, 2005). A baixa diversidade de espécies animais nos agroecossistemas avaliados pode ser atribuída a escassez de mão de obra familiar, dedicada a horticultura, a principal atividade de cultivo e que exige dedicação intensiva.

\section{Indicadores de Sustentabilidade de Situação Econômica e trabalho}

Pelo indicador "diversidade de produtos comercializados" (hortaliças, frutas, carnes, derivados animais), observou-se grande diversificação de produtos nos agrossistemas (Tabela 3), o que garante a comercialização durante todo o ano segundo os agricultores. Durante o período de chuva, evidenciase queda na produção de hortaliças em consequência da incidência de doenças. A justificativa dos agricultores é a falta de estrutura adequada para a produção, a exemplo de construção de estufas, e de tecnologias apropriadas como cultivares adaptadas a região.

Ressalta-se ainda, que a comercialização realizada, na maioria, com os produtos in natura, não contribui com agregação de valor aos mesmos. Observou-se maior diversidade de produtos nos agroecossistemas IV e V (Tabela 3), entretanto em quantidades pequenas de comercialização, fato atribuído ao tamanho da propriedade e distância do local de comercialização. Em ambos os agrossistemas, as propriedades possuem apenas um hectare, são localizadas na região periurbana e os agricultores utilizam a área de maneira mais eficiente, ou seja, aproveitam melhor o espaço aumentando a diversidade. Com a facilidade de acesso à região urbana, há incentivo a produção de alguns produtos, em pequena escala, considerando-se que os consumidores vão até as propriedades em busca deles (relato de agricultores). Exemplo, nesse caso, é a produção de acerola de uma única planta, que gera produtos processados (polpas, geleias e compotas) comercializados ao longo do ano pelas propriedades dos agroecossistemas IV e $\mathrm{V}$.

Tabela 3 - Notas atribuídas aos indicadores de sustentabilidade de situação econômica e trabalho.

\begin{tabular}{|c|c|c|c|c|c|c|}
\hline & \multirow{2}{*}{ Indicador } & \multicolumn{5}{|c|}{ Agroecossistemas } \\
\hline & & $\mathrm{I}$ & II & III & IV & $\mathrm{V}$ \\
\hline \multirow[t]{6}{*}{ Situação econômica } & Ataque visível de pragas & 4 & 4 & 5 & 4 & 2 \\
\hline & Canais de comercialização & 5 & 3 & 3 & 5 & 5 \\
\hline & Diversidade de produtos comercializados & 3 & 2 & 2 & 5 & 5 \\
\hline & Controle custo produção & 3 & 4 & 4 & 2 & 2 \\
\hline & Acesso a crédito rural & 5 & 4 & 4 & 1 & 1 \\
\hline & Média Final & 4 & 3,4 & 3,6 & 3,4 & 3 \\
\hline \multirow[t]{4}{*}{ Trabalho } & Acesso a assistência técnica & 1 & 3 & 3 & 2 & 2 \\
\hline & Capacitação & 3 & 4 & 3 & 3 & 3 \\
\hline & Permanência dos filhos na terra & 5 & 4 & 5 & 2 & 1 \\
\hline & Média Final & 3 & 3,67 & 3,67 & 2,33 & 2 \\
\hline
\end{tabular}

Fonte: dados de campo. Alta Floresta/MT, dez/2012 a fev/2013.

Dentre os canais de comercialização utilizados pelas famílias agricultoras, destacam-se a venda direta ao consumidor na propriedade e/ou na feira, mercados varejistas e aos programas do Governo Federal (PAA e Merenda Escolar). A venda direta entre produtor ou associação de produtores e o consumidor é importante para os agricultores por possibilitar uma melhor remuneração e tende a diminuir o preço para o consumidor. 
Quando questionados sobre as vantagens de comercializar produtos orgânicos para os programas do governo federal, alguns agricultores relataram que, embora seja uma alternativa viável de comercialização e agregação de valor ao produto, há dificuldades de receber os $30 \%$ no valor de seus produtos, além da "burocracia" considerada um fator limitante para os agricultores, fato que diminui a preferência por essa forma de comercialização.

O controle do custo de produção é um fator preocupante, principalmente para os agroecossistemas IV e V. Apenas os agroecossistemas II e III se preocupam em fazer anotações de custos de produção nas propriedades, enfatizando o pouco conhecimento dos agricultores quanto ao controle financeiro da produção. O planejamento e controle financeiro da produção são importantes para o sucesso econômico da atividade agrícola, uma vez que contribuem com informações importantes para a tomada de decisões (CHIAVENATO, 1991). Entretanto, observa-se um controle informal, sem detalhes, realizado pelos agricultores.

Com relação ao indicador "acesso a crédito rural", observou-se que esse, nos agroecossistemas IV e V , comprometem a resiliência econômica do agroecossistema. O crédito rural, aliado a outras políticas de inclusão, desempenha um importante papel na geração de trabalho e renda para a Agricultura Familiar, e assume um papel de gerador de oportunidades, possibilitando ao agricultor avanços tecnológicos e melhorias nas estruturas da propriedade.

No que se refere a incidência de pragas, apenas o agroecossistema V apresentou situação preocupante. Trata-se de um agroecossistema no início do processo de transição agroecológico, constituído ainda de parte da área com produção orgânica e parte com produção convencional. Os agroecossistemas I, II, III E IV, já em um estágio de transição mais avançado, apresentam maior equilíbrio no que se refere ao ataque de pragas. Como os parâmetros desse indicador foram obtidos por meio de observações a campo e de entrevistas com os agricultores, recomenda-se a realização de trabalhos com utilização de metodologia científica para avaliar as condições fitossanitárias dos agroecossistemas no decorrer do ano.

Em geral, na avaliação dos Indicadores de Sustentabilidade de Trabalho (Tabela 3), constatou-se que, dentre os principais impasses enfrentados pelos agricultores, está o desafio de acesso à assistência técnica pública. Esse serviço de apoio ao agricultor familiar é um instrumento de fundamental importância para o desenvolvimento dos agroecossistemas familiares, uma vez que possibilita a difusão e desenvolvimento de novas tecnologias, a potencialização do intercâmbio de conhecimentos e de acesso a informações (tais como a disponibilidade de crédito).

Quanto a permanência dos filhos na terra, fator importante para a manutenção do agroecossistema, os resultados obtidos nas entrevistas evidenciam o receio dos jovens quanto às atividades desenvolvidas pela família. Eles acreditam que, na cidade, terão outras oportunidades, com trabalhos menos desgastantes, não precisando assumir o acúmulo de atividades dos seus pais, como observado na fala de um agricultor transcrita a seguir.

Os meus filhos não quiseram trabalhar na roça. Eu até entendo, por que aqui o trabalho é duro. Eu trabalho de 10 a $12 \mathrm{~h}$ por dia, de domingo a domingo. Ele fala: por que eu vou trabalhar aqui se eu posso ter um emprego pra trabalhar 8 horas e descansar no final de semana? Na verdade eles querem é emprego e não trabalho [...]. (Agricultor, dez/2013)

$\mathrm{Na}$ cidade há muito atrativo para os jovens, inclusive pra trabalho. Eles não querem nem saber de ficar aqui... aqui a gente planta e tem que rezar pra colher, se não, não tem dinheiro. Lá não, todo final de mês ele sabe que vai sair o salário. (Agricultor, dez/2013)

Essa situação tem sido evidenciada em outras regiões do país, onde os limites impostos pela escassez da terra, da baixa renda das famílias, consequentemente, de investimento na produção e o não acesso a bens e serviços básicos (educação, lazer, etc.) levam os jovens a buscar melhores oportunidades de trabalho e qualidade de vida nas cidades (CAMARANO e ABRAMOVAY, 1999).

\section{Indicadores de Sustentabilidade de Qualidade de vida}

Na Tabela 4, são apresentadas as médias dos Indicadores de Sustentabilidade referentes à Qualidade de vida. 
Tabela 4 - Notas atribuídas aos indicadores de sustentabilidade de qualidade de vida.

\begin{tabular}{|c|c|c|c|c|c|}
\hline \multirow{2}{*}{ Indicador } & \multicolumn{5}{|c|}{ Agroecossistemas } \\
\hline & I & II & III & IV & $\mathrm{V}$ \\
\hline Estado de saúde da família & 5 & 4 & 4 & 3 & 2 \\
\hline Condições de Moradia & 4 & 4 & 4 & 4 & 4 \\
\hline Satisfação do agricultor com a atividade & 5 & 3 & 4 & 3 & 3 \\
\hline Acesso a lazer & 4 & 3 & 3 & 4 & 3 \\
\hline Média Final & 4,5 & 3,5 & 3,75 & 3,5 & 3 \\
\hline Relação com a terra & 5 & 5 & 5 & 4 & 3 \\
\hline
\end{tabular}

Fonte: dados de campo. Alta Floresta/MT, dez/2012 a fev/2013.

As notas para os indicadores de sustentabilidade de qualidade de vida variaram de 3,0 (regular) a 4,5 (boa). Todas as famílias possuem boas condições de infraestrutura do lar, com acesso aos principais equipamentos domésticos, bem como água encanada e energia elétrica. Porém, em nenhum dos agroecossistemas a família tem acesso à internet.

Com relação à saúde, a situação é "sofrível" no agroecossistema V uma vez que a agricultora responsável pela produção e gestão da propriedade, além de hipertensa, apresenta sérios problemas na coluna. Além disso, na família, há relatos da ocorrência de casos de intoxicação por agrotóxicos, fato que motivou ao abandono da forma de cultivo empregada e é o principal motivo do início da produção orgânica na propriedade. Nos demais agrossistemas, acredita-se que o bom estado de saúde dos agricultores se deva, em parte, ao sistema de produção agroecológico adotado, por agregar qualidade de vida às pessoas envolvidas (premissa da agricultura orgânica).

Para o indicador "satisfação do agricultor com a atividade", as notas variaram de 3 a 5 (Tabela 4) indicando que é uma situação boa e que representa a perspectiva dos agricultores continuarem praticando agricultura orgânica. A insatisfação de alguns agricultores é atribuída a falta de apoio das políticas públicas, de assistência técnica e algumas dificuldades encontradas na gestão da comercialização.

Para o indicador "Relação com a terra" que significa a sua trajetória de vida e sua relação com a atividade agrícola, os resultados são bons para os agrossistemas I, II, III e IV e regular para o agroecossistema V (Tabela 5). A relação do agricultor familiar com a terra não se baseia somente na produção para a comercialização, mas ele se identifica com o lugar em que trabalha e vive (modo de vida). Segundo Canuto, Silveira e Marques (1994, p.61), nos sistemas de organização familiares "a ecologia não representa somente a base de sua estrutura de produção, mas uma dimensão abrangente, relacionada à totalidade da vida do agricultor e fundamento de reprodução social da família". Por esse motivo a agricultura familiar se apresenta com um grande potencial para a transição do modelo de agricultura convencional para outros sistemas de agricultura de base ecológica.

Além disso, Toledo (2002) ressalta que o saber empírico do agricultor e o conhecimento sobre os ecossistemas em que convive, geralmente resultam em estratégias multidimensionais de uso da terra. São conhecimentos já testados pelo tempo, e que, portanto, coevoluiram com as mudanças ambientais e culturais vivenciadas pelas gerações de agricultores. Por meio desses conhecimentos é possível obter informações importantes para desenvolvimento de estratégias adequadas a sua realidade (ALTIERI, 2004).

\section{Indicadores de Sustentabilidade de Autodependência}

Na Tabela 5, são apresentados os resultados atribuídos aos indicadores de sustentabilidade de autodependência. Observou-se desempenho variando de crítico $(1,5)$ a bom $(4,5)$.

O principal fator limitante nos agroecossistemas estudados refere-se a baixa capacidade de desenvolvimento/adaptação de 'tecnologias apropriadas' ${ }^{6}$ as características locais. Os agricultores familiares, inseridos na Amazônia mato-grossense, buscaram reproduzir o sistema produtivo dominante na região (produção de grão e gado) considerado insustentável economicamente para pequenas áreas. Recentemente, alguns desses agricultores têm buscado converter suas unidades de produção para atividades como a horticultura, fruticultura e a avicultura, entretanto, têm se deparado com dificuldades no acesso e na adoção das tecnologias existentes. Por exemplo, a pouca disponibilidade no mercado de cultivares de hortaliças adaptadas as condições amazônicas.

${ }^{6}$ O termo é mais bem discutido em Herrera (1981) e Schumacher (1973). 
Tabela 4 - Notas atribuídas aos indicadores de sustentabilidade de qualidade de vida.

\begin{tabular}{|c|c|c|c|c|c|}
\hline \multirow{2}{*}{ Indicador } & \multicolumn{5}{|c|}{ Agroecossistemas } \\
\hline & $\mathrm{I}$ & II & III & IV & $\mathrm{V}$ \\
\hline Desenvolvimento/adaptação de tecnologias & 1 & 5 & 5 & 1 & 1 \\
\hline Certificação orgânica* & 4 & 4 & 4 & 1 & 1 \\
\hline Dependência de insumos & 5 & 4 & 4 & 3 & 3 \\
\hline Participação cooperativismo/associação, etc. & 2 & 5 & 5 & 1 & 1 \\
\hline Média Final & 3 & 4,5 & 4,5 & 1,5 & 1,5 \\
\hline
\end{tabular}

Fonte: dados de campo. Alta Floresta/MT, dez/2012 a fev/2013.

* Neste caso consideram-se como certificação os três Mecanismos de Controle para a Garantia da Qualidade Orgânica descritos em lei (certificação, sistema participativo de garantia- SPG e Controle Social pela Venda Direta sem certificação).

A não participação em "cooperativismo/associação" é um ponto limitante para a sustentabilidade dos agrossistemas, a exemplo dos agrossistemas II e III. De acordo com Finatto e Corrêa (2010), essas entidades desempenham uma função fundamental para a agroecologia, pois, na maioria das vezes, é por meio delas que o agricultor consegue garantir acesso à assistência técnica, realização de cursos e a busca por alternativas de comercialização.

\section{Apresentação dos resultados de forma integrada}

Para facilitar a análise e entendimento do comportamento integrado dos indicadores de sustentabilidade, optou-se pela visualização de gráfico do tipo radial. Na Figura 1 observa-se uma visão geral das notas atribuídas aos indicadores e que muitas situações são comuns a mais do que um agroecossistema.

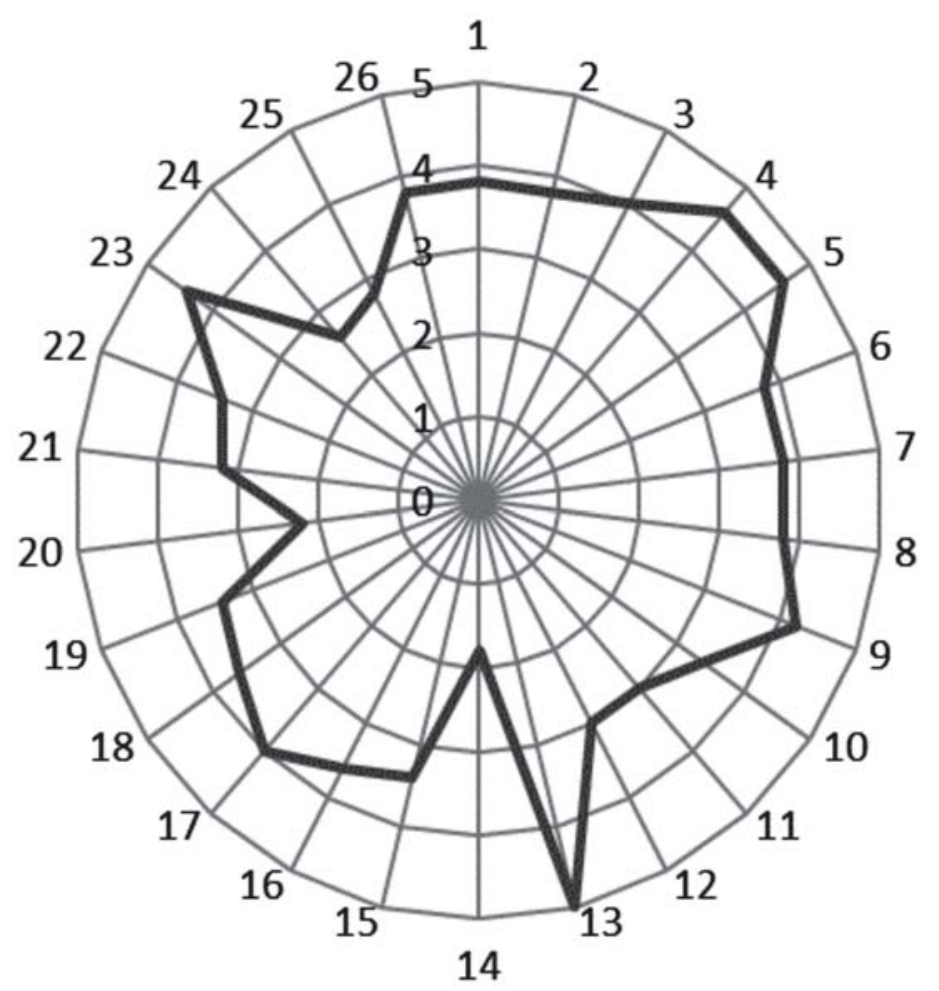

Figura 1 - Apresentação gráfica da média dos Indicadores de sustentabilidade dos agroecossistemas orgânicos familiares, Alta Floresta /MT, Brasil.

Fonte: Do autor

1. Disponibilidade de recursos hídricos (número de fontes e acesso; 2. Uso da água (Irrigação - uso e "eficiência"); 3 . Fertilidade do solo (pH, Matéria Orgânica, $\mathrm{Ca} 2+, \mathrm{Mg} 2+, \mathrm{A} 13+, \mathrm{P} 2 \mathrm{O} 5, \mathrm{~K} 2 \mathrm{O}, \mathrm{V} \%)$; 4. Matéria orgânica com origem propriedade (\% de M.O. produzida na UP em relação ao total utilizado);5. Uso de implementos agrícolas; 6. Área com erosão visível; 7. Diversidade de técnicas agroecológicas; 8. Ataque de pragas visível (análise qualitativa geral, média de todas as culturas); 9. Canais de comercialização; 10. Diversidade de produtos comercializados; 11. Controle custo de produção; 12. Crédito rural; 13. Diversidade de espécies vegetais manejadas; 14. Diversidade de espécies animais manejadas; 15. Reserva legal/APP (conservação); 16. Estado de saúde da família; 17. Condições de moradia; 18. Satisfação do produtor com o sistema de produção; 19. Acesso a lazer e cultura; 20. Acesso a Assistência técnica; 21. Capacitação (treinamentos, trocas de experiências, etc); 22 . Permanência dos filhos na terra; 23. Relação com a terra; 24. Desenvolvimento e/ou adaptação de tecnologias; 25. Certificação orgânica/comercialização orgânica; 26. Dependência de insumos. 
Na dimensão agroecológica, para os indicadores "diversidade de técnica agroecológica" e "ataque de pragas visível", observou-se desempenho regular e uma correlação entre esses dois indicadores, uma vez que não são utilizadas em todos os agrossistemas as técnicas agroecológicas que contribuem para o controle biológico dos insetos, a exemplo do cultivo de plantas atrativas de inimigos naturais e plantas repelentes, manutenção e manejo das plantas espontâneas, arranjo estratégico da produção, entre outros (SILVEIRA et al, 2009).

O não uso de técnicas agroecológicas nos agrossistemas avaliados é reforçado pelo resultado "sofrível" apresentado no indicador "acesso a assistência técnica", o qual indicou inoperância do sistema no município. Alves et al. (2009), relata que os agricultores familiares de Mato Grosso são extremamente carentes de assistência técnica, irrigação e fatores tecnológicos, situação potencializada pela inadequação das políticas públicas e poucas linhas de financiamento existentes. $\mathrm{O}$ indicador "acesso a crédito rural oficial" observado "sofrível" indica outro ponto de estrangulamento nos agrossistemas avaliados. As políticas de crédito possibilitam ao agricultor o acesso a algumas tecnologias, aquisição de instrumentos de trabalho e a ampliação da eficiência técnica permitindo assim o aumento da capacidade de "internalização" (como por exemplo, a substituição de adubação química por técnicas de adubação orgânica), acarretando na redução das externalidades.

Na dimensão econômica, pelo indicador "certificação orgânica", a situação "sofrível" decorrida da baixa agregação de valor nos produtos comercializados é acarretada pela pequena escala de produção, fato que dificulta a competição no mercado capitalista. A busca por nichos de mercado e segmentos específicos, com certeza, constituem alternativas para a melhoria das condições econômicas desses agricultores. Nesse aspecto, os agricultores orgânicos, de maior valor agregado, tornam-se uma estratégia competitiva viável ao produto (LIMA e WILKINSON, 2002). Os agricultores dos quatro agrossistemas manifestaram a importância da ampla divulgação dos benefícios da alimentação orgânica, o que poderá facilitar a comercialização do produto orgânico e a ampliar o conhecimento do consumidor final, a exemplo do que se observou no agrossistema $\mathrm{V}$, no qual a comercialização é direta na propriedade e há plena conscientização dos consumidores em relação à alimentação orgânica tida como "natural" e mais saudável.

Pelas análises do indicador "diversidade de produtos comercializados" observou-se situação "regular", o que demonstrou que, em geral, há pouca diversificação de produtos, sendo a comercialização mais comum dos produtos in natura, sem agregação de valor. Segundo os agricultores, isso se deve principalmente à escassez de recursos para investimento, por exemplo, em estufas e irrigação, associada à escassez de mão de obra. Além disso, embora haja, nos agrossistemas, riqueza de espécies manejadas, com grande potencial de mercado, muitas ainda são utilizadas para a alimentação familiar, ou seja, ainda não são exploradas comercialmente.

Para os indicadores "quantidade de espécies manejadas" e "matéria orgânica com origem na propriedade" o desempenho foi "bom". A maior quantidade de espécies manejadas reflete na maior oferta de produtos a serem comercializados, o que contribui na estabilidade socioeconômica da família (WANDERLEY, 2003; PELINSKI et al, 2006). Os agricultores avaliados cultivam uma espécie como principal mas também cultivam outras espécies para comercialização e/ou para subsistência. Essa diversificação de produtos animal e/ou vegetal, característica da agricultura familiar, além de contribuir para resistência às flutuações do mercado e imprevistos ambientais como clima, pragas, doenças e outros que podem afetar a produção, contribui com a oferta de produtos diversificados a serem comercializados, pelo agricultor, ao longo do ano, garantindo ainda a segurança alimentar da família. Técnicas de manejo como rotação de culturas, cultivos em faixas, cultivos intercalares, entre outras, assumem maior importância em manejo de agroecossistemas de base familiar.

\section{Considerações Finais}

Pela mensuração dos "indicadores de sustentabilidade" foram apontados os fatores favoráveis e desfavoráveis à sustentabilidade dos agroecossistemas avaliados. As principais limitações são a baixa capacidade de desenvolvimento e/ou de adaptação de tecnologias adequadas associadas à escassez de assistência técnica e número reduzido de produtos oriundos do sistema de cultivo orgânico. Entretanto, a produção eficiente da matéria orgânica na propriedade, o número reduzido de áreas com erosão visível, a grande diversidade de culturas manejadas, a forte relação com a terra e a satisfação do agricultor com o sistema de produção adotado são pontos que fortalecem a busca pelo ideal de sustentabilidade em agroecossistemas da Amazônia mato-grossense. 
Para o alcance da sustentabilidade dos agrossistemas, pelos resultados observados, faz-se necessário que os agricultores orgânicos se organizem para articular estratégias de comercialização e agregação de valor aos seus produtos; aumentar as atividades com a produção animal integrando-a a produção vegetal; além de um importante apoio do governo no sentido de promover ações extensionistas com enfoque na organização e associativismo dos agricultores e gestão das unidades de produção familiar.

\section{Fontes de Financiamento}

Coordenação de Aperfeiçoamento de Pessoal de Nível Superior (Capes) e Conselho Nacional de Desenvolvimento Científico e Tecnológico (CNPq) - concessão de bolsas.

\section{Agradecimento}

Aos agricultores e agricultoras que prontamente se disponibilizaram em participar e compartilhar suas histórias e conhecimentos.

\section{Referências bibliográficas}

ALTIERI, M. A. 2004. Agroecologia: a dinâmica produtiva da agricultura sustentável. 4 ed. Porto Alegre. UFRGS, 2004.

ALTIERI, M. A. 2004. Agroecologia: bases científicas para uma agricultura sustentável. Guaíba-RS: Agropecuária, 592 p., 2002.

ALVES, J.; FIGUEIREDO, A. M. R.; BOUNJOUR, P. D. S. C. M.; GOMES, M. B. A agricultura familiar em Mato Grosso. Revista Eletrônica Documento e Monumento, Cuiabá, v. 1, p. 69-86, 2009.

BERTONI, J.; LOMBARDI NETO, F. Conservação do solo. 4. ed. São Paulo. Ícone, 355 p., 1999.

CAMARANO, A. A.; ABRAMOVAY, R. Êxodo rural, envelhecimento e masculinizaçãa no BrasilPanorama dos últimas 50 anos. Rio de Janeiro. IPEA. 28p, 1999. (Texto para discussão $n^{0}$ 621).

CANUTO, J. C., SILVEIRA, M. A. da e MARQUES, J. F. Sentido da agricultura familiar para o futuro da agroecologia. Ciência e Ambiente, n 9, pp. 57-63. 1994.

CAPORAL, F. R.; COSTABEBER, J. A. Agroecologia: alguns conceitos e princípios.1.ed. Brasília. MDA/ SAF/DATER - IIICA, 24 p. 2004.

CASADO, Glória. I. G.; MOLINA, M. G.; GUZMAN, E. S. E MIELGO, A. M. A. Introducción a laagroecología como desarrollo rural sostenible. Madrid, Mundi-Prensa, 2000. 535 p.

CASALINHO, H. D. et al. Qualidade do solo como indicador de sustentabilidade. Revista Brasileira de Agrociência, v. 13, p. 195-203, 2007.

CLARO, S. A. Referenciais tecnológicos para a agricultura familiar ecológico: a experiência da região CentroSerra do Rio Grande do Sul. Porto Alegre: EMATER/RS-ASCAR, 241 p. 2001.

CHIAVENATO, I. Iniciação a administração de produção. São Paulo. Makron, McGraw-Hill. Cap. 5, p. 81-100, 1991.

COGO, N. P., DENARDIN, J.E.; BERTOL, I. e KOCHHANN, R.A. Retomada, redeûnição e intensidade da pesquisa em erosão do solo no Brasil. In: REUNIÃO BRASILEIRA DE MANEJO E CONSERVAÇÃO DO SOLO E DA ÁGUA: manejo integrado a ciência do solo na produção de alimentos, 15. Santa Maria - RS. UFSM, p.1-18, 2004.

COSTA, D. M. A., BARROS JÚNIOR, A. C. Avaliação da necessidade do reuso de águas residuais. Revista Holos, Ano 21, setembro, p. 82-101, 2005.

COSTA, S.S. Desmatamento e clima em Alta Floresta - Amazônia mato-grossense. Dissertação (mestrado) - Universidade Federal de Mato Grosso, Instituto de Ciências Humanas e Sociais, Pós-Graduação em Geografia, 2006. 
DECHEN, S. C. F. et al. Manejo de solos tropicais no Brasil. REUNIÃO BRASILEIRA DE MANEJO E CONSERVAÇÃO DO SOLO E DA ÁGUA: manejo integrado a ciência do solo na produção de alimentos, 15. Santa Maria - RS. UFSM, p.1-25. 2004.

DERPSCH, R. et al. Controle de erosão no Paraná: Sistemas de cobertura do solo, plantio direto e preparo Conservacionistas do solo. Eschborn, Alemanha: IAPAR/GTZ, 1991. 272 p.

FANTIN, E. Diversificação: um segredo da pequena unidade produtiva. Santa Maria: Revista Brasileira de Extensão Rural. V. 8, n. 1, p. 10-11. 1986.

FINATTO, R. A; CORRÊA, W. K. Desafios e perspectivas para a comercialização de produtos de base agroecológica - o caso do município de Pelotas/RS. Revista Brasileira de Agroecologia, v. 05, p. 95$105,2010$.

FULLER, A. From Part-time to Pluriactivity: a decade of Change in Rural Europe. Journal of Rural Studies, Great Britain. 6(4): p. 361-373,1990.

GLIESSMAN, S. R. Agroecologia: processos ecológicos em agricultura sustentável. 2. ed. Porto Alegre. UFRGS, 2001.

GLIESSMAN, S. R. Agroecologia: processos ecológicos em agricultura sustentável. $3^{\text {a }}$. Ed. Porto Alegre. Editora da UFRGS, 653 p., 2005. 1981.

HERRERA, A. The generation of technologies in rural areas. World Development.v: Nine, p: 21-35.

LIMA, D. M. A.; WILKINSON, J. (Org). Inovações nas tradições da agricultura familiar. Brasília. CNPq/Paralelo 15, 400p, 2002.

MARGARIT, E. O processo de ocupação do espaço ao longo da br-163: uma leitura a partir do planejamento regional estratégico da Amazônia durante o governo militar. Revista Geografia em Questão, volume 06, $\mathrm{n}^{\mathrm{o}}$ 1, p. 12-31. 2013.

MATTOS FILHO, A. M. Agricultura Orgânica sob a perspectiva da sustentabilidade: uma análise da região de Florianópolis - SC, Brasil. Dissertação [Mestrado] - Florianópolis: UFSC, 2004.

MASERA, O; ASTIER, M; LOPEZ-RIADURA S. Sustentabilidad y Manejo de Recursos Naturales: el marco de evaluación Mesmis. México. Mundi-Prensa, 1999. 109 p.

MARZALL, K. Indicadores de sustentabilidade para agroecossistemas. Dissertação (mestrado). Porto Alegre. Universidade Federal do Rio Grande do Sul. Porto alegre,1999. 2007.

MARZALL, K..(Org.). BR-163, de estrada dos colonos a corredor de exportação. Maringá. Ed. Massoni,

PELINSKI, A. et al. A diversificação no incremento da renda da propriedade familiar agroecológica. IV Congresso Brasileiro de Agroecologia, Belo Horizonte, 2006.

PICHININ, E. S. O contexto do avanço da fronteira agrícola na Amazônia: algumas reflexões sobre desenvolvimento regional no norte de Mato Grosso/MT. Revista Formação, volume 2, np 14, p. 70 79. 2007.

PRIMAVESI, A. Agroecologia e manejo do solo. Revista Agriculturas. v. 5, n. 3, p. 7-10. Set, 2008. PRIMAVESI, A. Manejo ecológico do solo: a agricultura em regiões tropicais. São Paulo: Nobel, 2002. SCHNEIDER, S. A pluriatividade na agricultura familiar. Porto Alegre. Editora da UFRGS, 2003.

SCHNEIDER, S.; CONTERATO, M. A. Transformações agrárias, tipos de pluriatividade e desenvolvimento rural: considerações a partir do Brasil. In: NEIMAN, G.; CRAVIOTTI, C. (Orgs.). Entre el campo y laciudad: desafíos y estratégias de lapluriactividadenel agro. Buenos Aires. Ediciones CICCUS, 2006.

SCHUMACHER, E. F. Small is beautiful: a study of economics as if people mattered. London. Blond e BriggsLtd., 1973.

SILVEIRA, L. C. P.; BERTI FILHO, E.; PIERRE, L. S. R.; PERES, F. S. C.; LOUZADA, J. N. C. Marigold (Tagetes erecta 1.) as an attractive crop to natural enemies in onion fields (Allium cepa L.). Scientia Agrícola (USP. Impresso), v. 66, p. 780-787. São Paulo. 2009.

TOLEDO, V. M. Agroecologia, sustentabilidad y reforma agrária, Porto Alegre. Agroecologia e Desenvolvimento Rural Sustentável, v. 3, n. 2, Jun. 2002. 57 p. 
VERDEJO, M. E. Diagnóstico rural participativo: guia prático DRP. Brasília. MDA / Secretaria da Agricultura Familiar, 62 p. il., 2006.

WANDERLEY, M.N.B. Raízes históricas do campesinato brasileiro. Mundo rural como um espaço de vida. Porto Alegre. Editora da UFRGS, p. 155-183, 2009.

WANDERLEY, M.N.B. Agricultura familiar e campesinato: rupturas e continuidade. Estudos Sociedade e Agricultura. Rio de Janeiro, p. 42-61, 2003.

Recebido para publicação em 12/2/2018 e aprovado em 21/8/2018. 